This item was submitted to Loughborough's Research Repository by the author.

Items in Figshare are protected by copyright, with all rights reserved, unless otherwise indicated.

The accuracy of a river bed moulding/casting system and the effectiveness of a low-cost digital camera for recording river bed fabric

PLEASE CITE THE PUBLISHED VERSION

PUBLISHER

(c) Blackwell

LICENCE

CC BY-NC-ND 4.0

REPOSITORY RECORD

Chandler, Jim H., Thomas Buffin-Belanger, Stephen P. Rice, lan Reid, and David J. Graham. 2019. "The Accuracy of a River Bed Moulding/casting System and the Effectiveness of a Low-cost Digital Camera for Recording River Bed Fabric". figshare. https://hdl.handle.net/2134/2236. 


\section{G Loughborough University}

This item was submitted to Loughborough's Institutional Repository by the author and is made available under the following Creative Commons Licence conditions.

\section{Cc) creative}

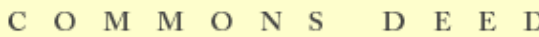

Attribution-NonCommercial-NoDerivs 2.5

You are free:

- to copy, distribute, display, and perform the work

Under the following conditions:

Attribution. You must attribute the work in the manner specified by the author or licensor.

Noncommercial. You may not use this work for commercial purposes.

No Derivative Works. You may not alter, transform, or build upon this work.

- For any reuse or distribution, you must make clear to others the license terms of this work.

- Any of these conditions can be waived if you get permission from the copyright holder.

Your fair use and other rights are in no way affected by the above.

This is a human-readable summary of the Leqal Code (the full license).

Disclaimer 민

For the full text of this licence, please go to: http://creativecommons.org/licenses/by-nc-nd/2.5/ 


\title{
THE ACCURACY OF A RIVER BED MOULDING/CASTING SYSTEM AND THE EFFECTIVENESS OF A LOW-COST DIGITAL CAMERA FOR RECORDING RIVER BED FABRIC
}

\author{
By J.H. CHANDLER (J.H.Chandler@lboro.ac.uk), \\ Department of Civil and Building Engineering, Loughborough University, \\ Loughborough, LE11 3TU, United Kingdom \\ T. BUFFIN-BÉLANGER (tbuffinb@uwo.ca) \\ S. RICE (S.Rice@lboro.ac.uk) \\ I. REID (Ian.Reid@lboro.ac.uk) \\ D.J. GRAHAM (D.J.Graham@lboro.ac.uk) \\ Department of Geography, Loughborough University, \\ Loughborough, LE11 3TU, United Kingdom
}

\begin{abstract}
Digital photogrammetry has been used to develop and test an artificial river bed moulding and casting system, which allows the pebbles within a coarse grain river bed to be recreated for hydraulic research in a laboratory flow channel or flume. Imagery of both the original streambed and the cast facsimile was acquired using a non-metric Kodak DCS460 digital camera and digital elevation models and orthophotographs were derived and compared to assess the accuracy of the moulding and casting system. These comparative tests proved to be critical in modifying and developing the system.

Additional imagery was obtained in the field using a non-metric Olympus C3030 "compact" digital camera to assess whether far cheaper camera technology could deliver data appropriate for such comparative examinations. Internal calibration parameter sets and data that were generated were compared with data obtained by the non-metric Kodak DCS460. These tests demonstrate that digital sensors built around high-quality $35 \mathrm{~mm}$ professional camera bodies and lenses are required for comparative examinations and for similar system development.
\end{abstract}

KEY WORDS: surface measurement, DEM, camera calibration, river bed studies.

Photogrammetric Record, 18(103): 2003

\section{INTRODUCTION}

Geomorphologists and hydraulic engineers strive to understand the complex interactions between the flow of water and entrainment of sediment in natural river channels. Experiments conducted within the controlled environment of a flume offer many advantages, but there are major difficulties reproducing river beds composed of coarse particles (pebbles, cobbles and boulders). Natural beds consist of complex arrangements of particles of wide-ranging size that have been deposited, reworked and oriented as a result of a large number of floods. The composite effect is a fluvial 'fabric' that is extremely difficult to reproduce in a flume. In the past, scientists have relied upon creating artificial pebble clusters (Lawless and Robert, 2001) or on numbering surface pebbles in the field in order to reconstruct a bed in the laboratory (Young, 1992). Although these techniques have provided significant results, these are derived in environments that lack the true complexity of real gravel-bed surfaces. Research conducted at Loughborough University has developed a novel system of casting a natural river bed and reproducing a realistic moulded replicate (BuffinBélanger et al., in press). However, a key research question was just how accurate was the cast replicate when compared with the original river bed surface. The primary purpose of 
this paper is to describe how digital photogrammetry was used to assess the accuracy of the river bed moulding/casting system and show how the derived spatial data were critical to successful development of the technique. A secondary objective is to compare and assess the effectiveness of two contrasting types of non-metric digital camera for such a task - the Kodak DCS460 and the Olympus C3030. The Kodak DCS460 has been successfully used for photogrammetric measurement but its successors remain expensive. The Olympus C3030 is more recent and comparatively cheap ( $£ 500$, March 2002). The Olympus has been successfully used for automatically extracting grain-size information from images of gravel river beds (Graham et al., submitted), but remains unproven for photogrammetric measurement.

\section{PAST AND RELATED PHOTOGRAMMETRIC WORK}

During the 1970s, the ability of analytical photogrammetry to correct for various systematic error sources led to the use of non-metric cameras for measurement (Schwidesky, 1970; Murai et al., 1980). Abdel-Aziz and Karara (1971) developed the pioneering Direct Linear Transformation (DLT), which was appropriate for $35 \mathrm{~mm}$ imagery without fiducial marks, but over-parameterisation of the solution introduced a lack of mathematical rigour. Rigorous approaches to model camera geometry were developed by Kenefick et al., (1972) and Faig $(1975,1976)$ and have subsequently been modified only slightly to compensate for affinity and differential scale associated with digital sensor systems (Fraser and Shortis, 1995; Patias and Streilein, 1996; Shortis et al., 1998). These methods have been used to measure particles and bedforms in a variety of studies. At extreme close range, Chiat (1977) used tilted images on a microscope stage to measure the size and shape of small particles typically less than $1 \mathrm{~mm}$ in size. Collins and Moon (1979) measured stream-bank erosion in the field environment, whilst

Photogrammetric Record, 18(103):, 2003

Welch and Jordan (1983) used a $35 \mathrm{~mm}$ amateur camera and enlarged transparencies to derive a digital elevation model (DEM) of a river bed within a small channel. In a series of studies, Lane et al., (1994, 1995, 1996) applied analytical photogrammetry using oblique photographs in conjunction with field surveying methods to monitor change that was occurring within an active pro-glacial stream in the Alps. Lane et al., (2000) also provided a comprehensive review of photogrammetric methods employed by fluvial geomorphologists, particularly for measuring the complex topography within a streambed and to estimate stream channel change. Developments in digital photogrammetry have been significant, offering the opportunity to extract DEMs automatically, and Stojic et al., (1998), Butler et al., (1998), Westaway et al., (2000) and Chandler et al., (2001) have all used this facility to measure bed forms created in both real and simulated river channels. The massive increase in point density afforded by automated DEM extraction methods suggests that manual measurements using traditional methods offer few advantages (Hancock and Willgoose, 2001). Automated methods have even been attempted where the measurement of bed forms takes place through an air/water interface (Butler et al., 2002; Wolff and Förstner, 2000).

In most of the recent studies involving digital photogrammetry, use has been made of either a semi-metric camera (typically a modified Hasselblad) with digital scanning of the original negatives, or a digital camera such as the Kodak DCS460. Examination of the recent photogrammetric literature suggests that the Kodak DCS460 and its predecessors (DCS420/DCS200) are acceptable for many photogrammetric measurement tasks (Fraser and Shortis, 1995; Peipe and Schneider, 1995; Ganci and Shortis, 1996; Fraser, 1997). In two recent studies, Chandler demonstrated that this class of camera is certainly capable of measuring river bed forms accurately, using both vertical (Chandler et al., 2001) and oblique (Chandler et al., 2002) imagery. Although results are good, the disadvantage with this class of camera remains the cost, even the current equivalent model (DCS760) costs in excess of $£ 7000$ (March 2002). There is, therefore, a desire to utilise cheaper image acquisition tools, particularly amongst non-specialists keen to use photogrammetric methods.

\section{The River Bed Moulding And CASTING TeCHNIQUe}

The casting technique is fully described in Buffin-Bélanger et al. (in press), so it is only necessary to provide a brief description of the technique here. The method involves classical sculpting: a mould of the object, the bed surface, is made and the mould is used subsequently to replicate the object in the form of a cast. Although quite straightforward in 
principle, using such a technique to replicate complex river bed surfaces of a relatively large area $(1$ by $2 \mathrm{~m})$ constituted a real challenge.

A polyvinyl chloride, commercially known as Gelflex ${ }^{\mathrm{TM}}$, is used to create the mould. The Gelflex is melted and poured over a selected dry bed surface, around which a metal retaining frame is placed. The Gelflex penetrates into the interstices and covers the bed surface with a flexible skin that can be peeled off. It is necessary to create a more rigid structure on top of the flexible Gelflex to preserve

Photogrammetric Record, 17(9\#), 200\# 3

the gross morphology of the bed, before removing the whole from the bed. Polyurethane foam resin was used because it cures quickly (within minutes) and has considerable strength on setting. As the foam expands and cures, surface irregularities ensure that it becomes mechanically locked to the underlying Gelflex. The entire mould can be then lifted onto its side, intact within the pre-positioned metal frame and embedded pebbles removed. This task is relatively easy because of the self-lubricating properties of the Gelflex. When cleaned and taken into the laboratory, the mould presents a negative impression of the gravel surface, with coral-like Gelflex prominences that reflect variably deep and complex interstices. Epoxy and polyurethane resins are then used to create the cast. When the casting is finished, the mould can be inverted in order to remove the polyurethane foam and the Gelflex mould. The cast provides a highly realistic surface in which great detail in the original is preserved.

\section{Testing the Accuracy of the Simulated River Bed Surface}

The moulding and casting system provided a river-bed replicate surface that looked realistic but quantitative data were required to assess the accuracy of the river bed moulding and casting system. Two separate photogrammetric surveys were carried out. Initially, the original river bed surface was measured in the field, prior to creation of the mould. Then, once the cast had been created in the laboratory, a second photogrammetric survey of the final cast surface was conducted. The same 3D rectangular Cartesian coordinate system was used in both photogrammetric surveys, to allow direct comparison and quantification of the accuracy of the system.

\section{River bed survey}

In the first survey, high-resolution digital images were acquired of the dry streambed using a Kodak DCS460. The camera was supported by a four-legged platform to ensure

stability during exposure from a height of $1.6 \mathrm{~m}$ above the bed (Figures 1a, 1b, 2). Fourteen premarked photo-control points were placed on prominent stones and coordinated to submillimetre precision using a digital theodolite, intersection methods, and a least-squares "variation of coordinates" estimation program. Eight of these points were constructed from targets $5 \mathrm{~mm}$ in diameter, the other six were the tops of "No. 6" chipboard screws inserted directly into the stream bed. Five vertical images of the test area were acquired using the Kodak DCS460, comprising two stereo pairs for DEM extraction, each with a base-todistance ratio of 1:6, and with a stereo overlap of $90 \%$ (Figure 1b). An additional camera position (Figure $1 \mathrm{~b}$ ) provided a single image over the whole area for orthophoto production. In addition, oblique and convergent images were obtained to provide appropriate geometry and redundancy to calibrate the DCS460 camera. Digital imagery was also acquired using an Olympus 3030 from a height of just $1.0 \mathrm{~m}$. A simple stereo pair configuration was adopted using a base-todistance ratio of approximately 1:5, a typical configuration that a nonspecialist might adopt for routine capture of field data. This was supplemented with four oblique images for calibration, the camera being set in all cases, with a fixed focus

Photogrammetric Record, 18(103):, 2003

distance. Table I provides a summary of the two camera specifications and configurations.

\begin{tabular}{lcccc} 
Camera & $\begin{array}{c}\text { Resolution } \\
\text { (pixels) }\end{array}$ & $\begin{array}{c}\text { Focal length } \\
(\mathrm{mm})\end{array}$ & $\begin{array}{c}\text { Flying Height } \\
(\mathrm{m})\end{array}$ & $\begin{array}{c}\text { Ground dimension } \\
\text { of pixel }(\mathrm{mm})\end{array}$ \\
\hline DCS460 & $3060 \times 2064$ & 24 & $1 \cdot 6$ & $0 \cdot 6$ \\
Olympus & $2048 \times 1536$ & 14 & $1 \cdot 0$ & $1 \cdot 0$
\end{tabular}

Table I, Camera details and configurations 


\section{River bed photogrammetry}

Processing of these data was carried out using the Erdas OrthoBASE ProfessionalC system. The eight targets were used as control points with an assigned precision of $\pm 1 \mathrm{~mm}$, whilst the six screw heads were classified as 'check points' and therefore not used in the restitution process directly. The software was used to manually measure the image coordinates of the control points and collect a series of tie points using an auto-tie facility. This latter operation was not entirely successful, primarily because part of the structure necessary to support the camera and indeed the author's footwear appeared within the photographs taken (Figure 2). These features shifted in location for successive images and these unstable interest points inevitably caused the software confusion. Once an initial adjustment had been achieved successfully, the measurements were processed using both the self-calibrating capabilities of OrthoBASE Professional and an independent self-calibrating bundle adjustment called GAP (Chandler and Clark, 1992). This duplication was carried out to provide confidence that the OrthoBASE software could derive appropriate estimates for the unspecified parameters used to model the inner geometry of the Kodak digital camera. The impact of including just one of the oblique images in conjunction with the five vertical images was also examined, to assess whether the stronger geometry would indeed assist in the self-calibration process.

Table II indicates the accuracy of the restitution process, providing rms error values for both the control and check points under two different photo-configurations and using two different camera calibration solutions. Solution "Obase Pro" utilised a "14 parameter Brown" solution, with the additional parameters being considered as weighted variables (Erdas, 2001). Unfortunately, the software manual provides little insight into these parameters and what they physically relate to, other than: "This model has fourteen additional parameters that are simplified from the suggestion of Dr. Brown" (Erdas, 2001). In contrast, the "GAP" solution incorporated three parameters to model the primary inner orientation (focal length, displacement of the principal point) and two parameters to model radial lens distortion (Kenefick et al., 1972; Chandler and Clark, 1992).

The results conveyed in Table II suggest that both calibration methods produced virtually identical results, providing confidence and confirming perhaps,

Photogrammetric Record, 17(9\#), 200\#

Solution rms error control rms error check

Total Image Unit Weight

( $\mathrm{mm})$ (8 points) ( $\mathrm{mm})$ (6 points)

\begin{tabular}{|c|c|c|c|c|c|c|c|c|}
\hline $\begin{array}{c}\text { Self- } \\
\text { calibration } \\
\text { method }\end{array}$ & $\begin{array}{c}\text { Oblique } \\
(\mathrm{Y} / \mathrm{N})\end{array}$ & $X$ & Y & Z & $X$ & Y & Z & $(\mu \mathrm{m})$ \\
\hline GAP & Y & $0 \cdot 7$ & $0 \cdot 1$ & 0.9 & $0 \cdot 7$ & 0.7 & 0.9 & $3 \cdot 7$ \\
\hline Obase Pro & Y & 0.7 & $0 \cdot 1$ & $0 \cdot 9$ & $0 \cdot 7$ & $0 \cdot 4$ & $0 \cdot 8$ & $3 \cdot 6$ \\
\hline GAP & $\mathrm{N}$ & $0 \cdot 5$ & $0 \cdot 2$ & $0 \cdot 5$ & $0 \cdot 5$ & $0 \cdot 5$ & $1 \cdot 6$ & $1 \cdot 6$ \\
\hline Obase Pro & $\mathrm{N}$ & $0 \cdot 5$ & $0 \cdot 2$ & $0 \cdot 4$ & $0 \cdot 5$ & $0 \cdot 5$ & $1 \cdot 1$ & $1 \cdot 1$ \\
\hline
\end{tabular}

Table II, rms error values of Kodak DCS460 restitution

the applicability of the OrthoBASE self-calibrating bundle adjustment solution for this imagery. Inclusion of one oblique image degraded the image unit weight ( $1 \cdot 1$ to $3 \cdot 6 \mu \mathrm{m})$, confirmed by a worsening of the accuracy of fit to the control $(0.4$ to $0.9 \mathrm{~mm})$. However, accuracy with respect to the independent check points actually improved slightly $(1 \cdot 1-0 \cdot 8$ $\mathrm{mm}$ ), demonstrating the value of oblique imagery for self-calibration and independent check points for assessing the quality of restitution.

Once a satisfactory restitution had been achieved, DEMs were generated from the two overlapping stereo-pairs and then merged to form a composite DEM. This was then used in conjunction with the single central image covering the whole test area (Figure 1b), to generate an orthophotograph representing the original stream bed as it appeared in the field. 
Figure 3 represents an unedited DEM of the original streambed derived from the DCS460 imagery, captured at $5 \mathrm{~mm}$ resolution or post-spacing. All major pebbles are represented and no gross errors are apparent. An acceptable quality of the DEM is confirmed by examining the root mean square errors of the DEM at the six check points (Table III), for the two different photo-configurations and self-calibration processing options.

Self-calibration method Oblique Elevation rms error (Y/N) (mm)

GAP Y 1.9 Obase Pro Y $1 \cdot 8$ GAP N $3 \cdot 0$ Obase Pro N $2 \cdot 2$

Table III, rms error values of DCS460 DEM at six check points

Photogrammetric Record, 18(103):, 2003

This reveals that an accuracy of $1.8 \mathrm{~mm}$ was achieved using OrthoBASE calibration routines, combined with the full configuration of images. A similar result $(1.9 \mathrm{~mm})$ was achieved using the same image set and an external camera calibration solution. Interestingly, the removal of just one oblique photograph degraded the accuracy of the DEM slightly to $2.2 \mathrm{~mm}$, implying again, the prudence of acquiring oblique imagery to assist in the camera calibration process. Overall, these results suggest that the quality of the extracted DEM is appropriate, as perhaps would be expected with this type of non-metric camera with proven capabilities ( $c f$. Fraser and Shortis, 1995; Peipe and Schneider, 1995; Ganci and Shortis, 1996; Fraser, 1997; Chandler et al., 2001; Chandler et al., 2002).

\section{Laboratory Survey and Photogrammetry}

The second phase of the photogrammetry involved extracting similar data, but using imagery acquired of the replicated river bed cast, in the laboratory. The same image configuration and camera platform was used (Figure 1b) but only DCS460 imagery was acquired. Three of the original screw heads and three of the original targets appeared in the cast, to which five new photo-control points were added. As before, the positions of these targets were determined in a 3D Cartesian coordinate system, using theodolite intersection methods. To achieve meaningful spatial comparisons between the two photogrammetric surveys, it was necessary to adopt the same object coordinate system in both the field and laboratory environments. Photo-control points common to both the field and laboratory surveys were used to compute the seven parameters of a 3D similarity transformation. Once these parameters were established, all laboratory photo-control points were transformed to the coordinate system used originally in the field. Data extracted and representing the cast could be then be directly compared with the original field dataset.

\section{ACCURACY EVALUATIONS}

\section{Accuracy of the moulding and casting system}

Figure 4 represents an orthophotograph of the replicated cast derived from the DSC460 imagery. A simple comparison with the original image (Figure 1) demonstrates how much detail the casting system is able to record and represent, to the extent that they appear virtually identical. However, the key research question is just how accurate is the surface morphology of the cast when compared with the original riverbed? Figure 5a is a colour map of elevation difference, derived by subtracting the river bed DEM from the cast DEM measured in the laboratory. Figure $5 \mathrm{~b}$ is just one cross section through this accuracy surface at the location marked in Figure 5a. Differences are comparatively small over larger areas, typically less than 3-5 mm, as depicted in the left hand side of the cross section. This suggests general conformity between the two surfaces and implies that the moulding and casting system has been both

Photogrammetric Record, 17(9\#), 200\#

effective and broadly accurate. There are three type-regions where differences are more significant and these discrepancies need to be discussed and explained.

The largest area of difference is centred on the ellipse " $A$ " (Figure 5a) and identifiable 
towards the right hand side of the cross section (Figure 5b), where a systematic pattern exhibiting large differences up to $30 \mathrm{~mm}$ is apparent. These discrepancies had actually been identified during the establishment of the seven parameters of the 3D similarity transformation. The residual for one of the control points in the area, a target, had been $32 \mathrm{~mm}$. It was assumed originally that this point had been perhaps knocked or displaced and was therefore excluded from the initial solution. However, the DEM of difference demonstrates that the discrepancies cover a much larger area than a localised target. Certainly some form of systematic error is present, either in the photogrammetry or the casting procedure. It was not possible to attribute this to the photogrammetry because the error was apparent in the control point residual prior to conducting any photogrammetric processing. The original casting in the field had been carried out in quite cold conditions $\left(4^{\circ} \mathrm{C}\right)$ and the polyurethane foam had not expanded as much as was hoped. The foam performs a critical role because it provides the rigidity required by the flexibility of the moulding agent. It is believed that this lack of rigidity allowed a slight twisting in the mould during transportation from the field to the laboratory, which was then reflected in the constructed cast. The differences in elevation detected are consistent with this theory and steps have now been taken to reduce this effect in future applications. Without the quantification provided by the photogrammetric assessment it is unlikely that this weakness in the casting and moulding method would have been identified.

The second example where large differences are apparent is for a few individual points around the periphery of large particles, (the stone located between $1 \cdot 28-1 \cdot 50 \mathrm{~m}$, Figure $5 \mathrm{~b}$ ). These small inaccuracies are due to the slightly differing camera positions, and are particularly apparent when recording high relief objects relative to flying height. This effect has been noted before (Butler et al., 1998; 2002) in a similar application. It is perhaps most familiar to photogrammetrists in the context of generating DEMs and orthophotos in urban areas (Skarlatos, 1999) where area-based cross correlation techniques are particularly ineffective in providing accurate height estimates where there are sharp discontinuities in the surface created by buildings. The third type of discrepancy is apparent within the areas occupied by very large particles ("B", Figure 5a), where there is a small systematic difference within the area defined by an individual particle. It is believed that these differences result from small distortions of the mould during the curing process of the epoxy resin, in the large holes in the mould that correspond to large clasts. The area covered by these imperfections is small and is only associated with the largest particles.

Despite these small and localised discrepancies, conformance is generally very high and certainly demonstrates the accuracy of the casting system and its appropriateness for hydraulic flume work. A useful method that can be adopted to rapidly identify differences in orthophotographs graphically, is to generate an animation. An animated sequence was derived from the orthophotographs of both

8 Photogrammetric Record, 18(103):, 2003

the original river bed (derived from Figure 2) and the laboratory cast (Figure 4). This animation is impossible to represent within a paper manuscript, but readers may access it at the following website: http://snap.lut.ac.uk/Jim/Images/ ManifoldMovie.gif. The animation provides a graphical and powerful way of demonstrating the degree of conformance of the moulding and casting procedure.

\section{Accuracy comparison of the DCS460 and Olympus C3030}

Additional imagery had been obtained in the field using a non-metric Olympus C3030 "compact" digital camera to assess whether far cheaper camera technology could deliver appropriate imagery for such photogrammetric comparisons. The restitution of the Olympus imagery adopted very similar processing steps to the DCS460 dataset. Initial results suggested poor accuracy, despite attempting a number of photo-configurations and calibration options provided by the OrthoBASE Professional software. The calibration options attempted included use of the three primary parameters of inner orientation and the 14 "Brown" parameters selected as weighted variables. Photo configuration options utilised either two vertical images plus three oblique images or just the two vertical frames. Table IV summarises the accuracies of restitution, under these differing processing scenarios. 


\begin{tabular}{|c|c|c|c|c|c|c|c|c|}
\hline $\begin{array}{l}\text { Self- } \\
\text { calibration } \\
\text { method }\end{array}$ & $\begin{array}{c}\text { Oblique } \\
(Y / N)\end{array}$ & rms & $\begin{array}{l}r \text { con } \\
\text { poin }\end{array}$ & (mm) & rms e & $\begin{array}{l}\text { chec } \\
\text { oints }\end{array}$ & am) $(6$ & $\begin{array}{c}\text { Total } \\
\text { Image } \\
\text { Unit } \\
\text { Weight } \\
(\mu \mathrm{m})\end{array}$ \\
\hline $\begin{array}{l}\text { Inner }+ \\
\text { Brown }\end{array}$ & $\mathrm{Y}$ & $4 \cdot 8$ & $4 \cdot 6$ & $2 \cdot 8$ & $3 \cdot 1$ & $4 \cdot 5$ & $2 \cdot 9$ & $17 \cdot 6$ \\
\hline $\begin{array}{l}\text { Inner }+ \\
\text { Brown }\end{array}$ & $\mathrm{N}$ & $5 \cdot 0$ & $5 \cdot 1$ & $4 \cdot 8$ & $2 \cdot 2$ & $3 \cdot 4$ & $13 \cdot 0$ & $11 \cdot 1$ \\
\hline Brown & $\mathrm{N}$ & $4 \cdot 6$ & $4 \cdot 4$ & $6 \cdot 0$ & $4 \cdot 0$ & $3 \cdot 1$ & $16 \cdot 1$ & $11 \cdot 3$ \\
\hline
\end{tabular}

Table IV, rms error values of Olympus C3030 restitution

The total image unit weight suggests that the optimum restitution was achieved by using the second processing option. However, closer examination reveals that the rms error fit to the control in height was $4.8 \mathrm{~mm}$, much larger than the first solution $(2.8 \mathrm{~mm})$. This option was derived using the full photo-configuration, combined with the 14 Brown and three primary inner orientation parameters. This is confirmed when the rms error for the six independent check points are examined; here, the first solution achieved $2.9 \mathrm{~mm}$ in height compared with $13.0 \mathrm{~mm}$ with the alternative processing options. It would therefore appear that the first processing option is perhaps the "best", although such a decision depends on whether the Total Image Unit Weight or the rms error derived from the check points, is perceived to be important.

If these results are compared with the accuracy of the DCS460 restitution (Table II), it is clear that the rms error fit to control, check point and total image unit weight are very much worse for the Olympus camera. The average accuracy

Photogrammetric Record, 17(9\#), 200\#

achieved with the DCS460 for all ordinates is less than $1 \mathrm{~mm}(0.7 \mathrm{~mm})$, whereas, for the Olympus, the average value is approximately $3 \mathrm{~mm}$. If DEMs extracted using these various calibration options are analysed, then the same view is confirmed. Table V tabulates the rms error of the extracted DEM for the same check points using the differing processing options. This suggests that the initial configuration provides the optimal solution for this particular camera, but, when compared with the DCS460 (Table 2, $1.9 \mathrm{~mm}$ ), we can see that this is an order of magnitude worse.

\begin{tabular}{ccc}
$\begin{array}{c}\text { Self-calibration } \\
\text { method }\end{array}$ & $\begin{array}{c}\text { Oblique } \\
(\text { Y/N) }\end{array}$ & $\begin{array}{c}\text { Elevation rms error } \\
(\boldsymbol{m m})\end{array}$ \\
\hline Inner + Brown & $\mathrm{Y}$ & $12 \cdot 6$ \\
Inner + Brown & $\mathrm{N}$ & $12 \cdot 9$ \\
Brown & $\mathrm{N}$ & $17 \cdot 4$
\end{tabular}

\section{Table V, rms error values of Olympus C3030 DEM at six check points}

Figure 6 represents a colour surface of difference derived by subtracting the DEM created by the Olympus camera from the same surface obtained by the DCS460. This demonstrates the spatial variation of difference and confirms the poor rms error achieved using the limited number of check points. Two comments are appropriate. There appears to be a domed structure within the differences, which is consistent with poor modelling of the inner geometry of the Olympus camera. This type of "domed structure" has been seen before (Stojic et al., 1998) and although it is easy to surmise that such a surface arises from inadequacies in lens modelling, the author believes that other uncertainties in inner camera geometry can be responsible (Stojic et al., 1998). Superimposed upon this pattern are clear influences of individual large stones. It is suggested that the relative variation of relief at these locations is large, which emphasises the differences arising from the poor modelling of the camera.

The resolution of the Olympus camera is only marginally lower than the DCS460 (Table I) and it may be slightly surprising that accuracies achieved using the Olympus 
C3030 are so much worse than those achieved using the Kodak DCS460. However, the two cameras are of very different design and cost. The DCS460 is built upon the rigid and expensive Nikon N90 camera body and utilises high quality optical lenses designed for professional photography. In contrast, the Olympus C3030 is aimed at a non-professional market purely concerned with obtaining digital imagery for multi-purpose use, in which spatial measurement is not considered. There has been some concern expressed in the photogrammetric literature regarding the instability of the CCD array in the DCS460 (Shortis et al., 1998) but for extracting DEMs from a vertical perspective at the levels of accuracy of 1-2 mm, such systematic error sources are insignificant; a fact which has been confirmed before (Chandler et al., 2001). While the accuracies achieved using the Olympus C3030 may be certainly appropriate for some applications, such as extracting grain size distributions (Butler et al., 2001; Graham et al.,

Photogrammetric Record, 18(103):, 2003

submitted), the recommendation must surely be to use the DCS460, or cameras of similar design, if photogrammetric measurement is intended.

\section{CONCLUSION}

Data derived by digital photogrammetry to represent both an original river bed and a cast facsimile have demonstrated and quantified the accuracy of a riverbed moulding and casting system. More significantly, analyses of these data sets have helped to improve the method involved in the production of the original mould. Further tests using imagery derived using both a Kodak DCS460 and the Olympus C3030 have confirmed the higher accuracies achievable with mature, non-metric professional camera technology. It is suggested that "compact" digital cameras should only be used for photogrammetric measurement if proven cameras are unavailable and only in situations where lower accuracy can be tolerated.

\section{ACKNOWLEDGEMENTS}

The research is sponsored by the Natural Environment Research Council under grant $\mathrm{NER} / \mathrm{B} / \mathrm{S} / 2000 / 00697$. The authors would also like to acknowledge the input from two anonymous referees.

\section{REFERENCES}

ABDEL-AZIZ, Y. I. and KARARA, H. M., 1971. Direct linear transformation from computer coordinates into object space coordinates. In: Close range photogrammetry. Falls Church: American Society of photogrammetry, pp $1-18$.

Buffin-BÉlanger, T., Reid, I., Rice, S., Chandler, J. H. and LANCASter, J., (In Press). A casting procedure for reproducing coarse-grained sedimentary surfaces. Accepted to Earth Surface Processes and Landforms.

Butler, J. B., LANE, S. N. and ChANDLER, J. H., 1998. Assessment of DEM quality for characterizing surface roughness using close range digital photogrammetry. Photogrammetric Record, 16(92): 271-291.

Butler, J. B., LANE, S. N. and ChANDLER, J. H., 2001. Automated extraction of grain-size data from gravel surfaces using digital image processing for hydraulic research. Journal of Hydraulic Research , 39(5): 519529.

Butler, J. B., LAne, S. N., Chandler, J. H. and Porfiri, E., 2002. Through-water closerange digital photogrammetry in flume and field environments. Photogrammetric Record, 17(99): 419-439. Chandler, J. H., Shiono, K., Rameshwaren, P. and LANE, S. N., 2001. Measuring flume surfaces for hydraulics research using a Kodak DCS460. Photogrammetric Record , 17(97): 39-61.

Chandler, J. H., Ashmore, P., PAOlA, C., GOOCH. M. J. and VARKARIS, F., 2002. Monitoring river channel change using terrestrial oblique digital imagery and automated digital photogrammetry. Annals of the Association of American Geographers. 92(4): 631-644.

CHANDLER, J. H. and ClARK, J. S., 1992. The archival photogrammetric technique: further application and development. Photogrammetric Record, 14(80): 241-247. CHIAT, B., 1977. The shape of small particles.

Photogrammetric Record, 9(49): 71-82. Collins, S. H. and Moon, G. C., 1979. Stereometric measurement of streambank erosion.

Photogrammetric Engineering \& Remote Sensing, 45(2): 183-190. ERDAS, 2001. Imagine OrthoBASE user's guide. Erdas Inc., 524pp. FAIG, I. W., 1975. Calibration of close range photogrammetric systems. Photogrammetric Engineering

\&Remote Sensing, 41(12): 1479-1486. FAIG, I. W., 1976. Photogrammetric potentials for non-metric cameras. Photogrammetric Engineering \&Remote Sensing, 42(1): 47-49.

Photogrammetric Record, 17(9\#), 200\#

FRASER, C. S., 1997. Digital camera self-calibration. ISPRS Journal of Photogrammetry \&Remote Sensing, 52: $149-159$. 
FrASER, C. S. and SHORTIS, M. R., 1995. Metric exploitation of still video imagery. Photogrammetric Record, 15(85): 107-122.

GRAHAM, D. J., REID, I., and RICE, S. submitted. Operationalising innovative image analysis to sediment characterisation. Part 1: image analysis. Earth Surface Processes and Landforms.

GANCI, G. and SHORTIS, M. R., 1996. A comparison of the utility and efficiency of digital photogrammetry and industrial theodolite systems. International Archives of Photogrammetry and Remote Sensing, 31(B5): 182187.

HANCOCK, G. and WiLlgoose, G. 2001. The production of digital elevation models for experimental model landscapes. Earth Surface Processes and Landforms 26 (5): 475-490.

KENEFICK, J. F., GYER, M. S. and HARP, B. F., 1972. Analytical self-calibration. Photogrammetric Engineering, 38(11): 1117-1126.

LANE, S. N., ChandLER, J. H. and Richards, K. S., 1994. Developments in monitoring and modelling small scale river bed topography. Earth Surface Processes and Landforms, 19(4): 349-368.

LANE, S. N., CHANDLER, J. H. and RiCHARDS, K. S., 1995. Within-reach spatial patterns of process and channel adjustment. Chapter 6 in River Geomorphology (Ed. E.J. Hicken). Wiley, Chichester. 255 pages: 105-130.

LANE, S. N., RichaRdS, K. S. and CHANDlER, J. H., 1996. Discharge and sediment supply controls on erosion and deposition in a dynamic alluvial channel. Geomorphology, 15(1): 1-15.

LANE, S. N., JAmes, T. D. and CROWELL, M. D., 2000. Application of digital photogrammetry to complex topography for geomorphological research. Photogrammetric Record, 16(95): 793-821.

LAWLESS, M., and ROBERT, A. 2001. Three-dimensional flow structure around small-scale bedforms in a simulated gravel-bed environment. Earth Surface Processes and Landforms, 26(5): 507-522.

MurAi, S., NAKAMURA, H., and SuZUKI, Y., 1980. Analytical orientation for non-metric camera in the application to terrestrial photogrammetry. International Archives of Photogrammetry, 23(5): 515 525.

PATIAS, P., and STREILEIN, A., 1996. Contribution of videogrammetry to the architectural restitution results of the CIPA "O. Wagner Pavillion" test. International Archives of Photogrammetry and Remote Sensing, 31(B5): 457-462.

PEIPE, J. and SCHNEIDER, C.-T., 1995. High resolution still video camera for industrial photogrammetry. Photogrammetric Record, 15(85): 135-139.

SCHWIDEFSKY, K., 1970. Precision photogrammetry at close ranges with simple cameras. Photogrammetric Record, 6(36):567-589.

Shortis, M. R., Robson, S. and BeYer, H. A., 1998. Principal point behaviour and calibration parameter models for Kodak DCS cameras. Photogrammetric Record, 16(92): 165-186.

Stojic, M., Chandler, J. H., Ashmore, P. and LUCE, J.,1998. The assessment of sediment transport rates by automated digital photogrammetry. Photogrammetric Engineering \& Remote Sensing, 64(5): 387-395. SKARLATOS, D., 1999. Orthophotograph production in urban areas. Photogrammetric Record, 16(94): 643-650. WELCH, R. and JORDAN, T.

R., 1983. Analytical non-metric close range photogrammetry for monitoring stream channel erosion. Photogrammetric Engineering \&Remote Sensing, 49(3): 367 374.

WestawAy, R. M., LANE, S. N. and HiCKS, D. M., 2000. The development of an automated correction procedure for digital photogrammetry for the study of wide, shallow, gravel-bed rivers. Earth Surface Processes and Landforms, 25(2): 209-226.

WOLFF, K. and FÖRSTNER, W., 2000. Exploiting the multi view geometry for automatic surfaces reconstruction using feature based matching in multimedia photogrammetry. International Archives of Photogrammetry and Remote Sensing 33(B5): 900-907.

YounG, W. J., 1992. Clarification of the criteria used to identify near-bed flow regimes. Freshwater Biology, 28(3): 383-391.

\section{FIGURES}

Photogrammetric Record, 18(103):, 2003

Fig 1a. Field site showing camera support and nature of site/river bed. (Note: Please convert to greyscale)

Fig 1b. Photo and control configuration for river (laboratory) using Kodak DCS460.

Fig 2. Kodak DCS460 image of real river bed (note: camera platform legs and the author's footwear)

Fig 3. DEM of river bed (derived using DCS460 imagery)

Fig 4. Orthophotograph of cast (derived using DCS460 imagery) Fig 5. DEM of difference (a) (Note: Colour agreed) and Transect (b)- (River - Lab) Fig 6. DEM of difference- (Kodak-Olympus) 
(Note: Colour agreed).
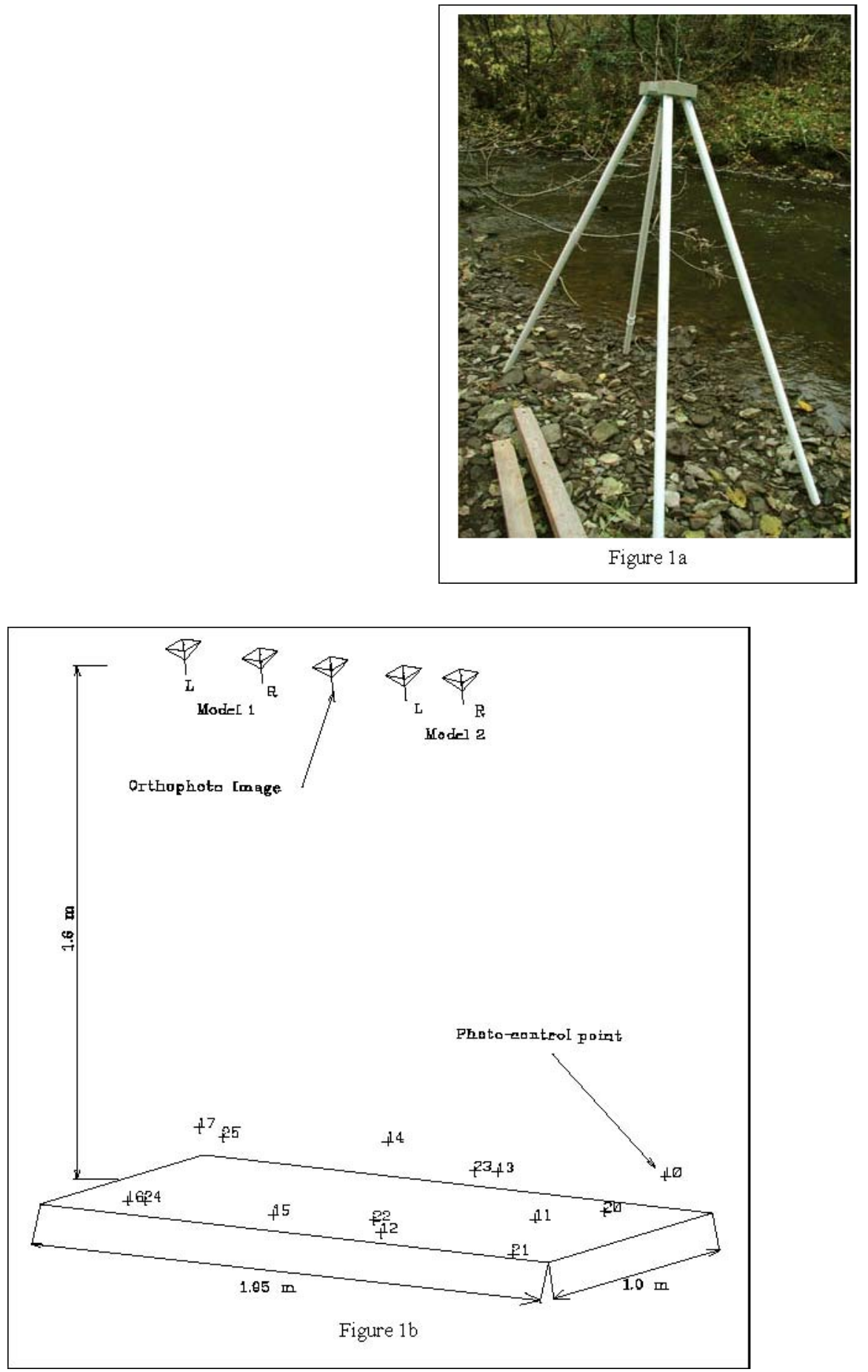

Photogrammetric Record, 17(9\#), 200\# 

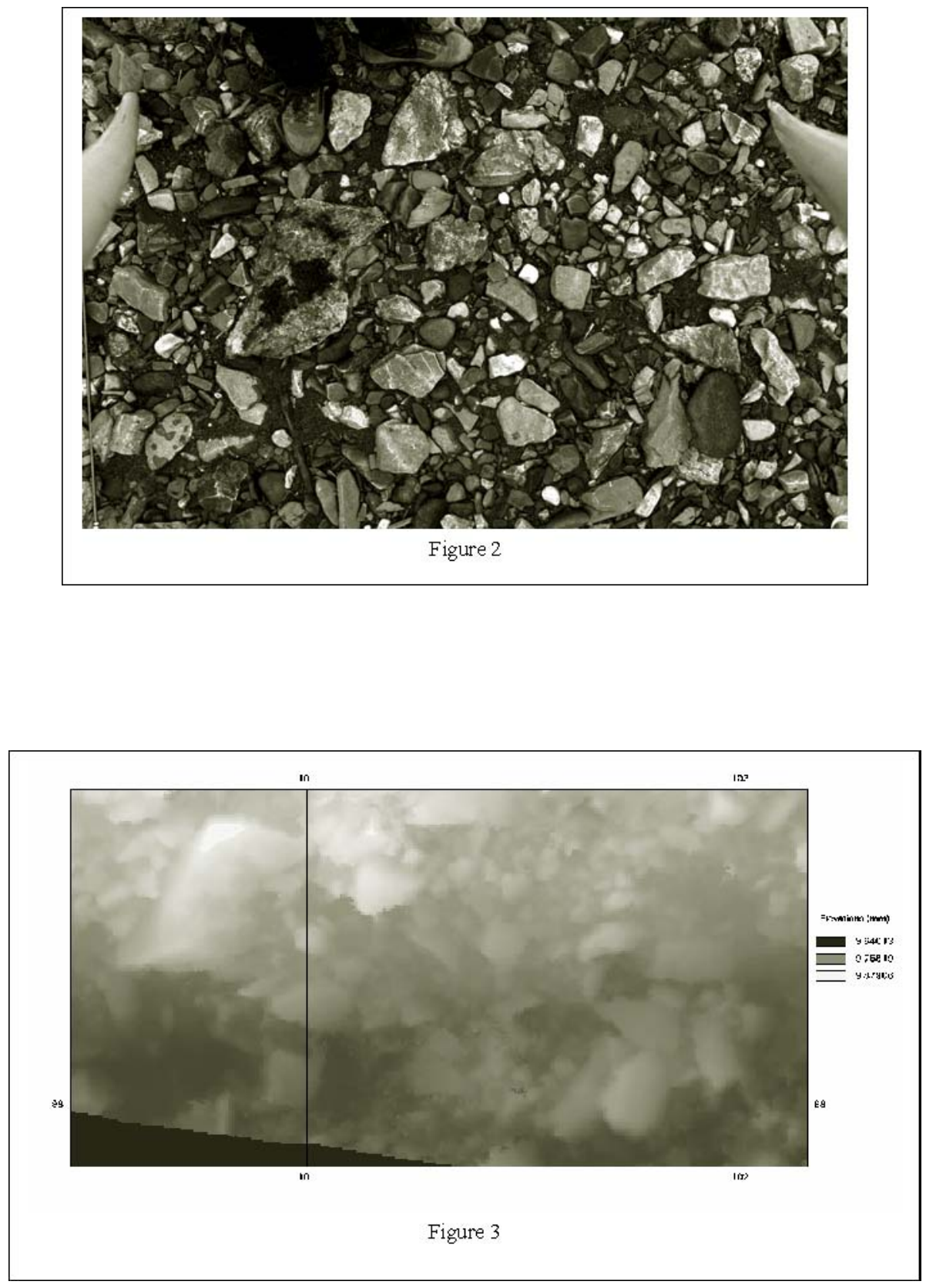

Photogrammetric Record, 18(103): 2003 

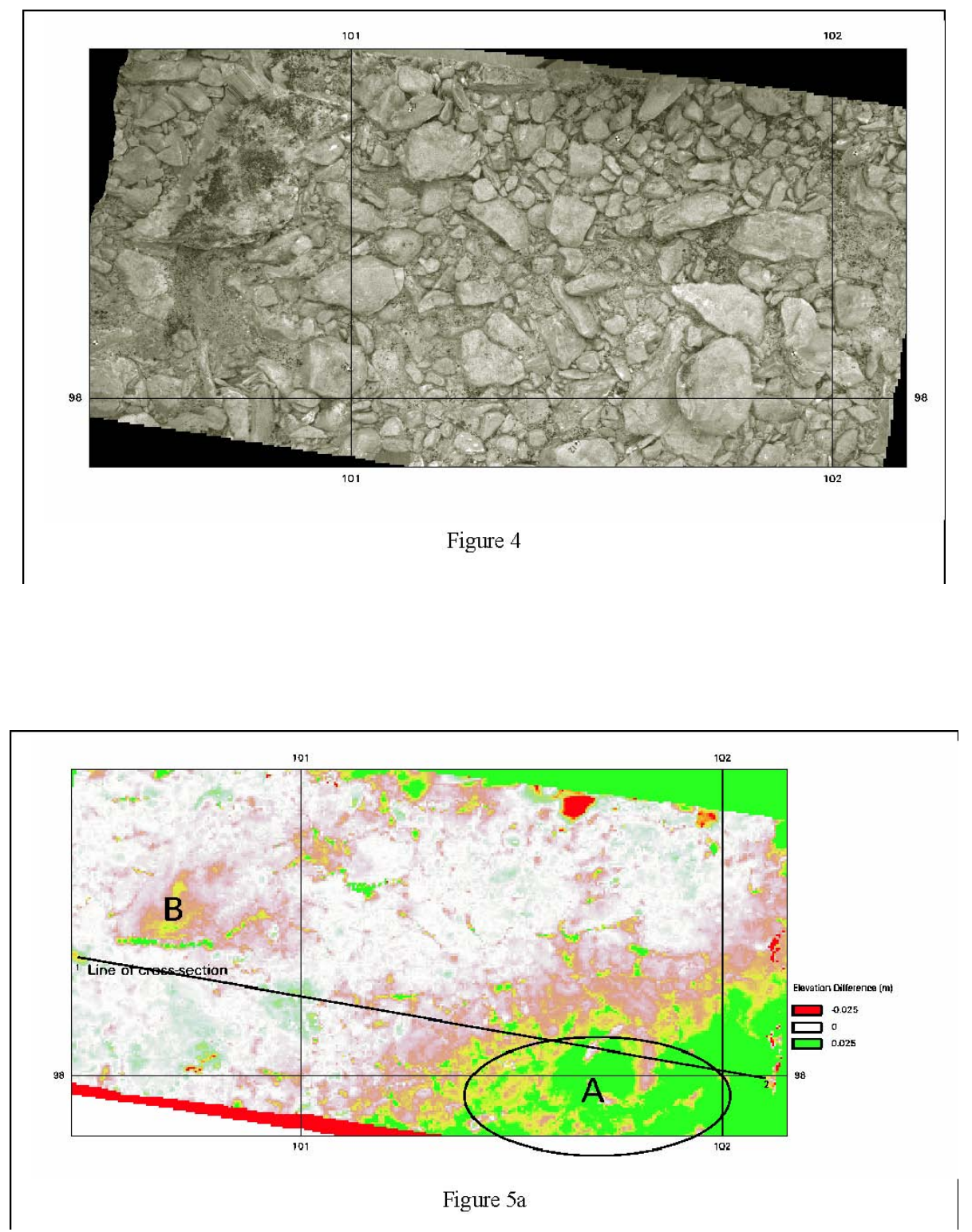

Photogrammetric Record, 18(103): 2003

(metres)

0.06

0.04

0.02

0.00

$-0.02$

0.001 .80

$-0.04^{1}$ (metres) 


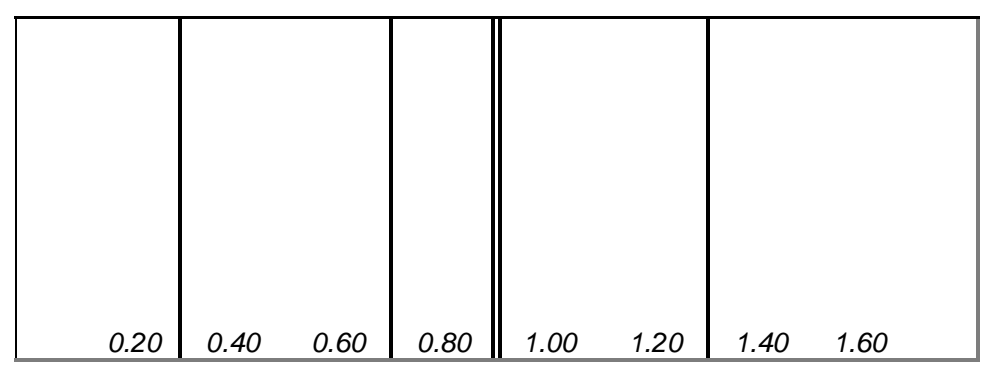

Figure $5 b$

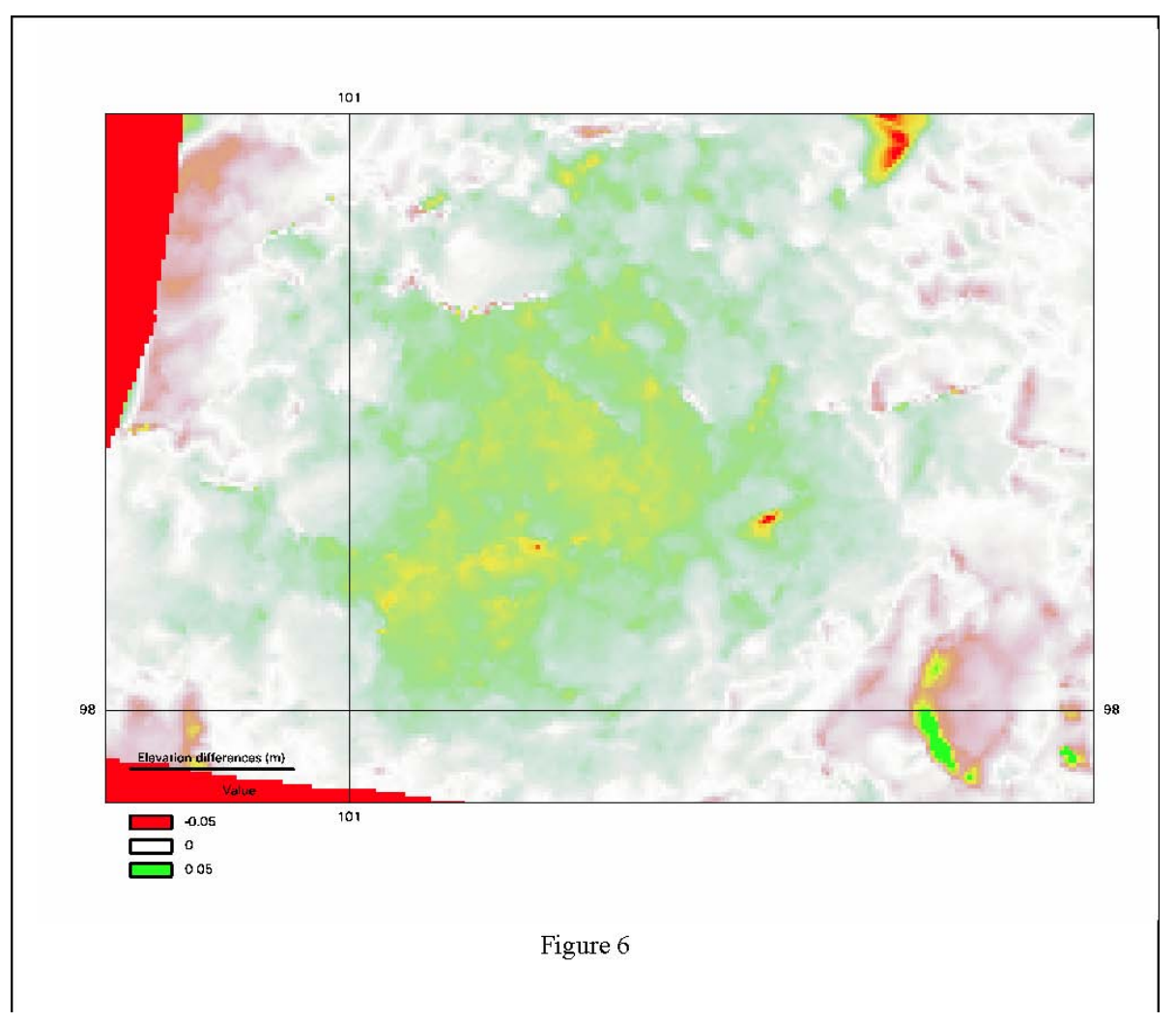

Photogrammetric Record, 18(103):, 2003 